ARTICLE

\title{
General synthesis of ultrafine metal oxide/reduced graphene oxide nanocomposites for ultrahigh-flux nanofiltration membrane
}

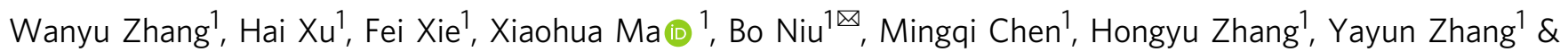
Donghui Long (1) ${ }^{1 凶}$

Graphene-based membranes have great potential to revolutionize nanofiltration technology, but achieving high solute rejections at high water flux remains extremely challenging. Herein, a family of ultrafine metal oxide/reduced graphene oxide ( $r G O)$ nanocomposites are synthesized through a heterogenous nucleation and diffusion-controlled growth process for dye nanofiltration. The synthesis is based on the utilization of oxygen functional groups on GO surface as preferential active sites for heterogeneous nucleation, leading to the formation of sub- $3 \mathrm{~nm}$ size, monodispersing as well as high-density loading of metal oxide nanoparticles. The anchored ultrafine nanoparticles could inhibit the wrinkling of the rGO nanosheet, forming highly stable colloidal solutions for the solution processing fabrication of nanofiltration membranes. By functioning as pillars, the nanoparticles remarkably increase both vertical interlayer spacing and lateral tortuous paths of the rGO membranes, offering a water permeability of $225 \mathrm{~L} \mathrm{~m}^{-2} \mathrm{~h}^{-1}$ bar $^{-1}$ and selectivity up to $98 \%$ in the size-exclusion separation of methyl blue.

\footnotetext{
${ }^{1}$ State Key Laboratory of Chemical Engineering, East China University of Science and Technology, Shanghai 200237, China. 凶email: niubo@ecust.edu.cn; longdh@mail.ecust.edu.cn
} 
$\mathrm{N}$ anofiltration is an energy-efficient membrane separation process that can reject efficiently multivalent ions and organic compounds, showing great promising in water treatment applications, and particularly in pharmaceutical and food industries ${ }^{1-4}$. Generally, the nanofiltration membranes have nanopores in the range of $0.5-5 \mathrm{~nm}$, which could the fulfill nominal molecular weight cutoff of $200-1000 \mathrm{Da}^{5,6}$. And the separation mechanism is majorly governed by the size-based and charge-based exclusion, which depends strongly both on the membrane structure and on the interaction between the membrane and the solute $e^{7,8}$.

Recently, a great advance has been made in the graphene-based membranes for nanofiltration ${ }^{9}$. Graphene is an up-and-coming 2D material with good flexibility, large surface area, excellent electrical conductivity, and high surface activity ${ }^{10}$. It thus has been considered as an ideal membrane material, especially for desalination ${ }^{11}$. More typically, the graphene oxide (GO) composed of graphite-like and oxidized region feature water migration and simultaneously highly efficient molecule sieving ${ }^{12}$. GO is dispersible in water and many other polar solvents, making it be easily fabricated into laminated membrane materials via solution processing techniques for nanofiltration separations ${ }^{13-18}$. The $2 \mathrm{D}$ interlayer spacing between GO nanosheets can be used as nanochannels for water permeation while rejecting the larger species ${ }^{19}$. And the interlayer spacing of GO nanosheets can be further adjusted to achieve size-selective molecular sieving ${ }^{20}$. However, GO nanosheets are extremely hydrophilic, causing uncontrollable swelling and poor stability of GO membranes in water environments ${ }^{21,22}$. Therefore, the reduced graphene oxide $(\mathrm{rGO})$ membranes with lower oxygen functional groups can provide better performances in precise molecular sieving, due to their narrower nanochannels, lower swelling, and higher stable in water or harsh chemical conditions 23,24 . Unfortunately, water permeation through the stacked GO or rGO membranes is insufficient due to the strong capillary force and the narrow nanochannels ${ }^{25}$

Broadening the interlayer spacings have been employed to modulate the water transport behaviors in GO membranes, generally via intercalation of soft polymers including cationic porphyrin $^{26}$, polyacrylonitrile gel ${ }^{27}$, polyelectrolyte brushes ${ }^{28}$.
However, incorporating polymer additives often cause very limited enhancement of water permeability, mainly owing to the intrinsic elastoplastic of the polymers and their uneven distribution on the GO surface 29,30 . In addition, the enlarged interlayer spacing will make a trade-off between permeability and selectivity, inducing significant rejection degradation ${ }^{31,32}$. It should be beneficial for tailoring the interlayer distance and improving membrane permeability if the intercalation materials are rigid and highly dispersed, but a practical intercalation strategy has remained elusive.

Herein, we report a general and facile colloidal synthesis to prepare ultrafine metal oxide/rGO nanocomposites for nanofiltration membranes. The synthesis is based on the utilization of oxygen functional groups on GO surface as preferential sites for fast heterogeneous nucleation, leading to the formation of sub$3 \mathrm{~nm}$ size, monodispersing as well as high-density loading of metal oxide nanoparticles on the rGO surface. The present synthesis is highly universal for anchoring various metal oxide nanoparticles, such as $\mathrm{ZnO}, \mathrm{CoO}, \mathrm{CuO}, \mathrm{MgO}, \mathrm{Fe}_{2} \mathrm{O}_{3}, \mathrm{Nb}_{2} \mathrm{O}_{5}, \mathrm{CdO}, \mathrm{La}_{2} \mathrm{O}_{3}$, and $\mathrm{MoO}_{3}$ and metal sulfides such as $\mathrm{ZnS}, \mathrm{MoS}_{2}$ nanoparticles. Moreover, the adhesion of these ultrafine nanoparticles could inhibit the wrinkling and restacking of the $\mathrm{rGO}$ nanosheet, forming highly stable colloidal solutions for low-cost solution processing of nanofiltration membranes. By functioning as rigid pillars, the nanoparticles not only increase the distance between the rGO sheets, but also create narrow tortuous paths among the 2D nanochannels for size-exclusion separation of dye molecules. The resulting membranes could realize high water permeability $\left(225 \mathrm{~L} \mathrm{~m}^{-2} \mathrm{~h}^{-1}\right.$ bar $^{-1}$ ) and selectivity (up to $98 \%$ ) of methyl blue, which places them among the most effective dye separation membranes reported to date. This study illustrates the utility of rigid nanoparticles as spacers for addressing the permeabilityselectivity trade-off of GO-based membranes, providing insights into the design of next-generation nanofiltration membranes.

\section{Results}

Synthesis and characterization of ultrafine $\mathrm{ZnO} / \mathrm{rGO}$ nanocomposites. Figure 1a illustrates a general heterogeneous nucleation and diffusion-controlled growth process of ultrafine metal oxide/rGO

(a)
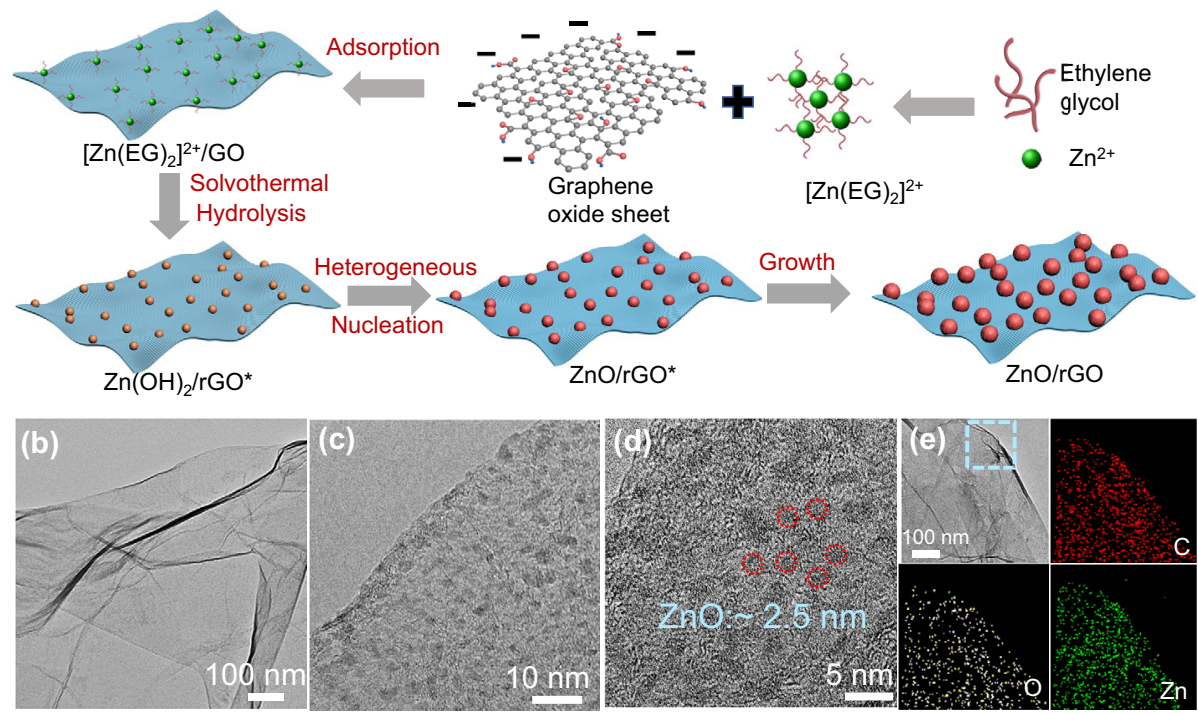

Fig. 1 Synthesis and characterization of ultrafine $\mathrm{ZnO} / \mathrm{rGO}$ nanocomposites. a Schematic illustration of the growth mechanism of ultrafine $\mathrm{ZnO} / \mathrm{rGO}$ nanocomposites. The whole process is an adsorption-nucleation-growth process. Firstly, positively charged $\left[\mathrm{Zn}(\mathrm{EG})_{2}\right]^{2+}$ complexes adsorbed to the negative charged $\mathrm{GO}$, and then transformed into $\mathrm{Zn}(\mathrm{OH})_{2}$ and $\mathrm{ZnO}$ successively during solvothermal process. Finally, ultrasmall $\mathrm{ZnO}$ nanoparticles grow to larger $\mathrm{ZnO}$ nanoparticles on $\mathrm{rGO}$ surface. b-d TEM images of ultrafine $\mathrm{ZnO} / \mathrm{rGO}$ nanocomposites at different magnifications. The red circles in $\mathrm{d}$ refer to $\mathrm{ZnO}$ nanoparticles. e TEM elemental mapping images of ultrafine $\mathrm{ZnO} / \mathrm{rGO}$ nanocomposites. 
nanocomposites using ultrafine $\mathrm{ZnO} / \mathrm{rGO}$ nanocomposites as an example. The GO is rich in oxygen functional groups, and it is supposed that these oxygen functional groups are responsible for the heterogeneous nucleation. More typically, in a mixed ethylene glycol (EG) solution of $\mathrm{GO}$ and zinc acetate dihydrates $\left(\mathrm{Zn}(\mathrm{Ac})_{2} \cdot 2 \mathrm{H}_{2} \mathrm{O}\right)$, the presence of oxygen groups which contributes to an overall negatively charged surface of $-40 \mathrm{mV}$ will capture the positively charged $\left[\mathrm{Zn}(\mathrm{EG})_{2}\right]^{2+}$ complexes through electrostatic interactions (Supplementary Fig. 1). Under solvothermal conditions, the adsorbed $\left[\mathrm{Zn}(\mathrm{EG})_{2}\right]^{2+}$ complexes could be hydrolyzed to adsorbed $\mathrm{Zn}(\mathrm{OH})_{2}$, which is equivalent to the formation of preferential sites. At such sites, the effective surface energy is lower, thus diminishes the free energy barrier and facilitating heterogeneous nucleation. The asformed nucleus will grow slowly via a diffusion-controlled growth process, leading to the formation of ultrafine and isolated island nanoparticles on the surface of rGO. The whole reaction process is schematically illustrated in Supplementary Fig. 2. Meanwhile, GO is reduced to rGO. As illustrated in Supplementary Fig. 3, GO is covalently functionalized with oxygen containing groups (hydroxyl, epoxide, carbonyl, etc.) on the basal plane and on the edges. These functional groups are unstable under high temperature. Thus, carbon monoxide $(\mathrm{CO})$, carbon dioxide $\left(\mathrm{CO}_{2}\right)$, and water $\left(\mathrm{H}_{2} \mathrm{O}\right)$ remove from $\mathrm{GO}$ surface during the solvothermal process, leading to the formation of rGO with lots of defects ${ }^{33}$.

The TEM images reveal that the as-prepared $\mathrm{ZnO} / \mathrm{rGO}$ nanocomposites has a very transparent laminated structure with less wrinkles and folding, which is similar to the pristine GO nanosheets (Fig. 1b). The high resolution TEM images (Fig. 1c, d) clearly demonstrate that the rGO surface is consisted of densely distributed $\mathrm{ZnO}$ nanoparticles with the size of ca. $2.5 \mathrm{~nm}$. Besides, energy dispersive X-ray spectroscopy (EDS) elemental mappings (Fig. 1e) also confirm that $\mathrm{ZnO}$ nanoparticles are distributed homogeneously within the rGO nanosheets. The weight ratio of $\mathrm{ZnO}$ in the composite is determined to be close to the designed value $50 \mathrm{wt} \%$ (Fig. 2f), suggesting that all $\mathrm{Zn}$ precursors participate fully the hydrolysis reaction to $\mathrm{ZnO}$.

Mechanism study of the formation of ultrafine $\mathrm{ZnO}$ nanoparticles on GO surface. To understand the nucleation and growth of $\mathrm{ZnO}$ nanoparticles on rGO surface, the time-dependent experiments were conducted. At the initial solvothermal time of $0.5 \mathrm{~h}$, the $\mathrm{ZnO}$ nanoparticles are already formed, but their size is only $1 \mathrm{~nm}$ corresponding to $\sim 20 \mathrm{ZnO}$ molecular clusters (Fig. 2a and Supplementary Fig. 4). With the time prolonging, the size gradually increases to ca. $2.5 \mathrm{~nm}$ at $3 \mathrm{~h}$ while remains unchanged until reaching to their final stage (Fig. 2b-e). It is interesting to note that the particle number density is almost the same of 9 per $10 \times 10 \mathrm{~nm}$ for all samples (Fig. 2e and Supplementary Fig. 5), which clearly indicates that the nucleation occurs simultaneously at GO surface and no new nuclei form during the growth process. This result implies that the particle number density should be depended on the surface characteristics of GO, more especially the number of oxygen functional groups.

To verify the structure and chemical state of the nanocomposites produced at the first few hours of solvothermal synthesis, the thermogravimetric (TG), X-ray photoelectron (XPS), and X-ray diffraction (XRD) characterizations were conducted. The weight ratio of $\mathrm{ZnO}$ in composites from TG results (Fig. 2f) has a similar increasing tendency with the size of $\mathrm{ZnO}$ nanoparticles. At the initial $0.5 \mathrm{~h}$, the weight ratio of $\mathrm{ZnO}$ nanoclusters is only $10 \mathrm{wt} \%$, and then gradually increases to the designed value of $50 \mathrm{wt} \%$ at $3 \mathrm{~h}$. It is noted that the $\mathrm{ZnO} / \mathrm{rGO}-0.5 \mathrm{~h}$ has a significant weight loss at temperature of $160-220^{\circ} \mathrm{C}$ in TG curve, which should be due to deoxygenation of incompletely reduced GO. This could be well confirmed by XRD pattern (Fig. $2 \mathrm{~g}$ ), in which the $\mathrm{ZnO} / \mathrm{rGO}$ -
$0.5 \mathrm{~h}$ exhibit two shoulder peaks centered at $11^{\circ}$ and $23^{\circ}$, responding to the characteristic of $\mathrm{GO}$ and $\mathrm{rGO}^{34,35}$, respectively. And after the further solvothermal reduction of $1 \mathrm{~h}$, the GO peak at $11^{\circ}$ disappears mostly and the peak at $23^{\circ}$ gets dominant, which indicates the coexistence of $\mathrm{rGO}$ and $\mathrm{GO}$ in $\mathrm{ZnO} / \mathrm{rGO}-1 \mathrm{~h}$. While the time increased to $2 \mathrm{~h}$, only a characteristic peak of rGO at $23^{\circ}$ could be discerned, verifying that the reduction of GO could be accomplished at the initial $2 \mathrm{~h}$ under solvothermal condition. And no obvious characteristic peaks could be discerned for the $\mathrm{ZnO}$ crystals, further confirming their ultrafine size. In addition, XPS patterns (Fig. 2h, $\mathrm{i}$ and Supplementary Figs. 6, 7) were carried out. The high resolution $\mathrm{C} 1 s$ spectrum of $\mathrm{GO}$ are deconvoluted into three major components, including $\mathrm{C}=\mathrm{C} / \mathrm{C}-\mathrm{C}(284.8 \mathrm{eV}), \mathrm{C}-\mathrm{O} / \mathrm{C}-\mathrm{O}-\mathrm{C}(286.1-287.1 \mathrm{eV})$ and $\mathrm{C}=\mathrm{O} /$ $\mathrm{O}-\mathrm{C}=\mathrm{O}(288.2-289.3 \mathrm{eV})^{36} . \mathrm{C}=\mathrm{C} / \mathrm{C}-\mathrm{C}$ is contributed to $s p^{2}$ and $s p^{3}$ hybridized carbon atoms disposed in two-dimensional GO layer, $\mathrm{C}-\mathrm{O} / \mathrm{C}-\mathrm{O}-\mathrm{C}$ is result from hydroxyl and epoxy, and $\mathrm{C}=\mathrm{O} /$ $\mathrm{O}-\mathrm{C}=\mathrm{O}$ exist in carbonyl and carboxyl ${ }^{37}$. Upon $0.5 \mathrm{~h}$ solvothermal reaction, the fraction of the $\mathrm{C}-\mathrm{C} / \mathrm{C}=\mathrm{C}$ groups in $\mathrm{C} 1 \mathrm{~s}$ spectra show a significant increase from $49 \%$ to $56 \%$, while the intensities of $\mathrm{C}=\mathrm{O}$ and $\mathrm{C}-\mathrm{O} / \mathrm{C}-\mathrm{O}-\mathrm{C}$ groups drop, which can be attributed to the breakup of oxygen functional groups (Fig. $2 \mathrm{~g}$ ). After reacting $3 \mathrm{~h}$, the intensity of $\mathrm{C}-\mathrm{C} / \mathrm{C}=\mathrm{C}$ groups in Supplementary Figs. 6, 7 further increases, and the proportion of $\mathrm{C}=\mathrm{O}$ groups remains drop, suggesting almost reduction of $\mathrm{GO}$ in $\mathrm{ZnO} / \mathrm{rGO}-3 \mathrm{~h}$. During the deoxygenated process, $\mathrm{CO}_{2}, \mathrm{CO}$, and $\mathrm{H}_{2} \mathrm{O}$ were produced, leading to decrease of $\mathrm{O}$ ratio and increase of $\mathrm{C}$ ratio. It should be noted that the $\mathrm{Zn} 2 p$ spectra (Fig. $2 \mathrm{j}$ ) for all samples are very similar with two obvious bands located at $1045.3 \mathrm{eV}$ and $1022.3 \mathrm{eV}$, corresponding to the $\mathrm{Zn}^{2+} 2 p_{1 / 2}$ and $\mathrm{Zn}^{2+} 2 p_{3 / 2}$, respectively ${ }^{38}$. All these results indicate that the reduction of GO and the growth of $\mathrm{ZnO}$ on rGO nanosheets could be accomplished at the initial $3 \mathrm{~h}$ under solvothermal conditions.

The key to the synthesis of ultrafine $\mathrm{ZnO}$ nanoparticles should be the oxygen functional groups on GO surface, which have binding ability toward $\mathrm{Zn}^{2+}$ through electrostatic attractions, and consequently trigger the heterogenous nucleation. According to the elemental analysis, GO used in this work has a $\mathrm{C} / \mathrm{O}$ ratio of ca.1.8. And XPS spectrum in Fig. $2 \mathrm{~h}$ reveals that it is consisted of majorly epoxide and carbonyl functional groups on the basal plane, and hydroxyl and carboxyl groups on its edges 39 . To get insights into the binding abilities of these oxygen functional groups with $\mathrm{Zn}^{2+}$ in $\mathrm{EG}$, we perform density functional theory (DFT) calculation and disclose that the order of adsorption stability toward $\mathrm{Zn}^{2+}$ is as follows: epoxy(-COC) > carbonyl $(-\mathrm{CO})>$ carboxyl $(-\mathrm{COOH})$ » hydroxyl $(-\mathrm{OH})$ (Fig. 3a). Furthermore, the reaction barriers of the hydrolysis of adsorbed $\mathrm{Zn}^{2+}$ and then its transformation to $\mathrm{ZnO}$ on GO surface and without GO are analyzed. The optimized structures of intermediates and their Gibbs free profiles are displayed in Fig. 3b, $c$ and Supplementary Table 1. The overall Gibbs free energy changes on oxygen functional groups $(-\mathrm{OH},-\mathrm{COC},-\mathrm{COOH}$, and $-\mathrm{CO})$ in EG reaction system are $-6.433 \mathrm{eV},-6.999 \mathrm{eV},-6.608 \mathrm{eV}$, and $-7.759 \mathrm{eV}$, respectively, which are all more negative than that of without GO $(-4.783 \mathrm{eV})$. The lower Gibbs Energy changes lead to smaller reaction barrier. The last step of $\mathrm{Zn}(\mathrm{OH})_{2} /$ $\mathrm{rGO}^{*} \rightarrow \mathrm{ZnO} / \mathrm{rGO}^{*}$ exhibits positive Gibbs energy change $(\Delta \mathrm{G})$, which infers this step is the thermodynamic-limiting step in the whole process. From the results of Gibbs energy changes, it can be concluded that the total transformation process of $\mathrm{Zn}^{2+}$ to $\mathrm{ZnO}$ is a spontaneous process and thermodynamically more favorable on GO surface. The carbonyl is suggested as the most active site for nucleation and followed by epoxy and carboxyl.

The controlled nucleation is triggered by the oxygen functional groups on GO surface due to the lower free energy barrier, while the consequent growth of $\mathrm{ZnO}$ nanoparticles should be a 


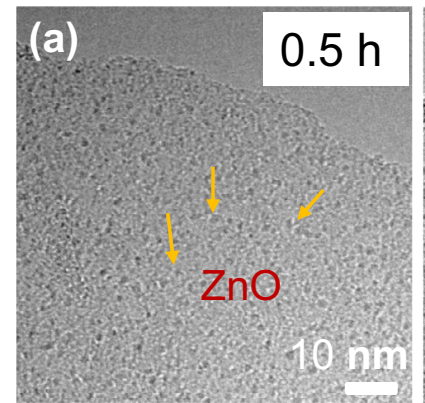

(e)

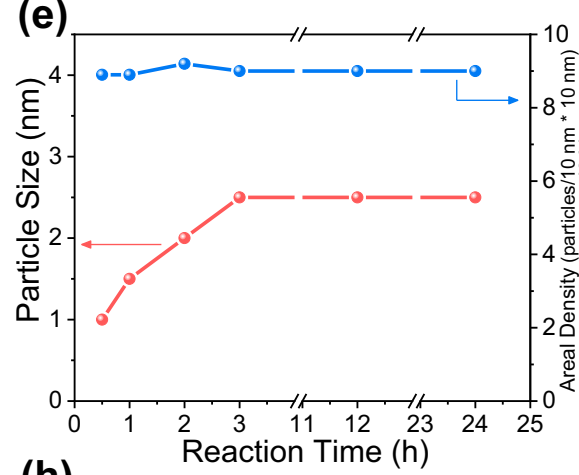

(h)

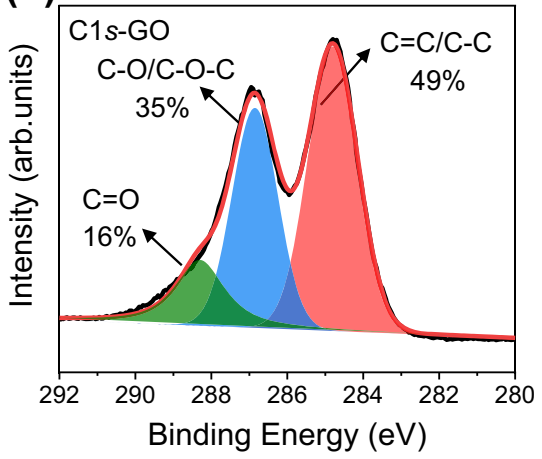

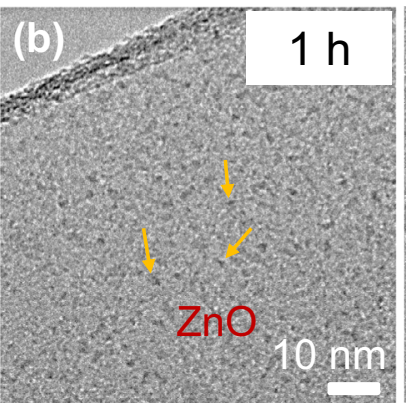

(f)

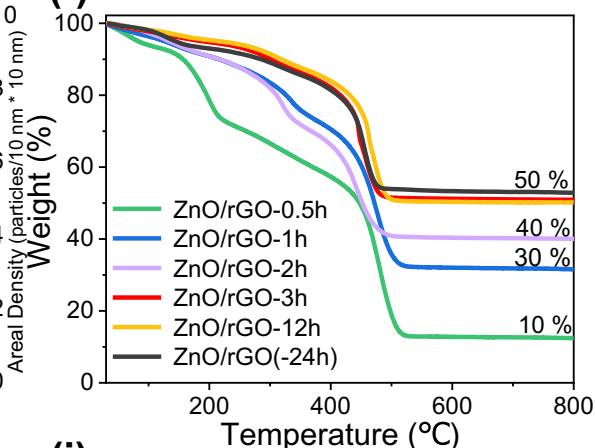

(i)

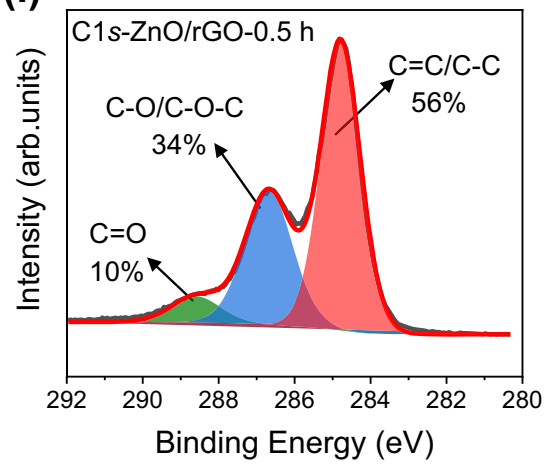

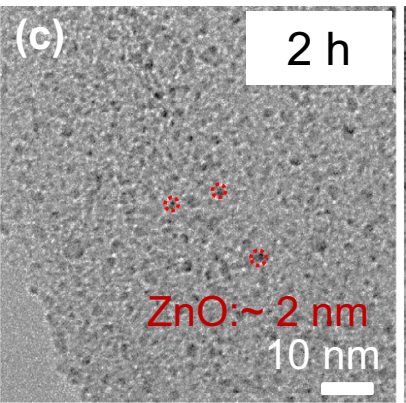

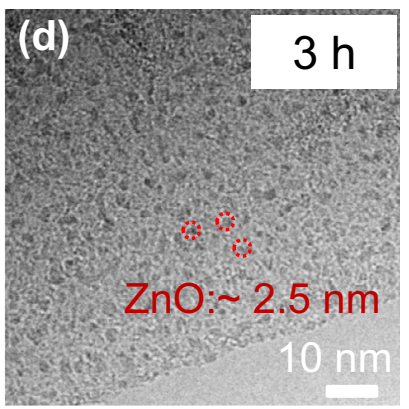

(g)

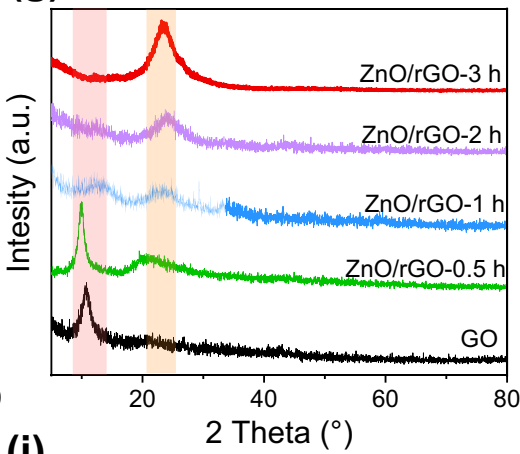

(j)

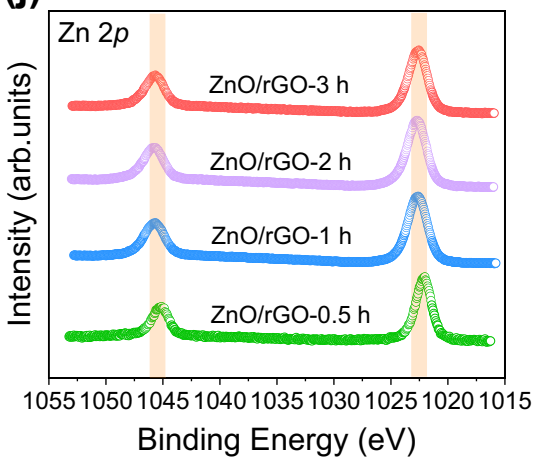

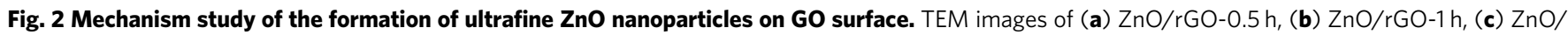
rGO-2 h, and (d) $\mathrm{ZnO} / \mathrm{rGO}-3 \mathrm{~h}$. The yellow arrows and red circles refer to $\mathrm{ZnO}$ nanoparticles. e Graph of the average $\mathrm{ZnO}$ particle size and particle number density over time. f TGA curves of various samples. The residual weight of every sample after annealing in air at $800{ }^{\circ} \mathrm{C}$ refers to the $\mathrm{ZnO}$ contents in nanocomposites, which is given on the ride hand of every curve. $\mathbf{g}$ XRD spectra of various samples. The red and yellow shadings represent the XRD characteristic peak of GO and rGO, respectively. C1s XPS spectra of (h) GO, (i) ZnO/rGO-0.5 h. j Zn $2 p$ XPS spectra of various samples. The yellow shadings represent the XPS characteristic peak of $\mathrm{Zn} 2 p$.

diffusion-controlled process that is limited by the rate of incorporation of adatoms into $\mathrm{ZnO}$ growth centers. Herein, the growth of $\mathrm{ZnO}$ nanoparticles on the rGO surface was studied through a series of control experiment by changing the reaction temperature. As shown in Supplementary Fig. 8a, the $\mathrm{ZnO} / \mathrm{rGO}$ nanocomposites prepared at temperature of $90{ }^{\circ} \mathrm{C}$ show ultrasmall $\mathrm{ZnO}$ nanoparticles of ca. $1.3 \mathrm{~nm}$. Such low nucleation temperature should be due to the lowering heterogenous nucleation barrier, while the small size should be caused by the limited diffusion at low temperature. With increasing the reaction temperature to $180^{\circ} \mathrm{C}$, the average size of $\mathrm{ZnO}$ nanoparticle increases gradually, but the particle number density keeps almost unchanged on the rGO surface (Supplementary Figs. 8-10). In addition, the concentration of precursor $\mathrm{Zn}(\mathrm{Ac})_{2} \cdot 2 \mathrm{H}_{2} \mathrm{O}$ was also changed to adjust the loading contents of $\mathrm{ZnO}$ in $\mathrm{ZnO} / \mathrm{rGO}$ nanocomposites. At a low precursor concentration, the TG curve reveals that the content of $\mathrm{ZnO}$ is $30 \mathrm{wt} \%$, being the same with the designed value (Supplementary Fig. 10b). However, the resulting nanocomposites (Supplementary Fig. 8d) show an almost transparent feature without the visible nanoparticles on the rGO surface, which should be due to the formation of ultrasmall $\mathrm{ZnO}$ clusters $(<1 \mathrm{~nm})$ that are hardly displayed by the TEM images. While the $\mathrm{ZnO}$ loading is larger than $50 \%$, the nanocomposites show almost similar morphologies of $\mathrm{ZnO}$ nanoparticles (Supplementary Figs. 8e, f, 10b).

Furthermore, the synthesis of pure $\mathrm{ZnO}$ particles without GO was conducted under the same solvothermal conditions. The obtained $\mathrm{ZnO}$ product shows spherical aggregates with size of ca. $600 \mathrm{~nm}$ (Supplementary Fig. 11), which should be due to the homogenous nucleation continued by the growth of primary nanoparticles and thereafter the spherical aggregation. In addition, the solvent is also critical for the formation uniform $\mathrm{ZnO}$ nanoparticles on the $\mathrm{rGO}$ surface. EG is selected as the solvent due to its strong chelating and reduction ability ${ }^{40}$. While changing solvent from EG to deionized water and ethanol 

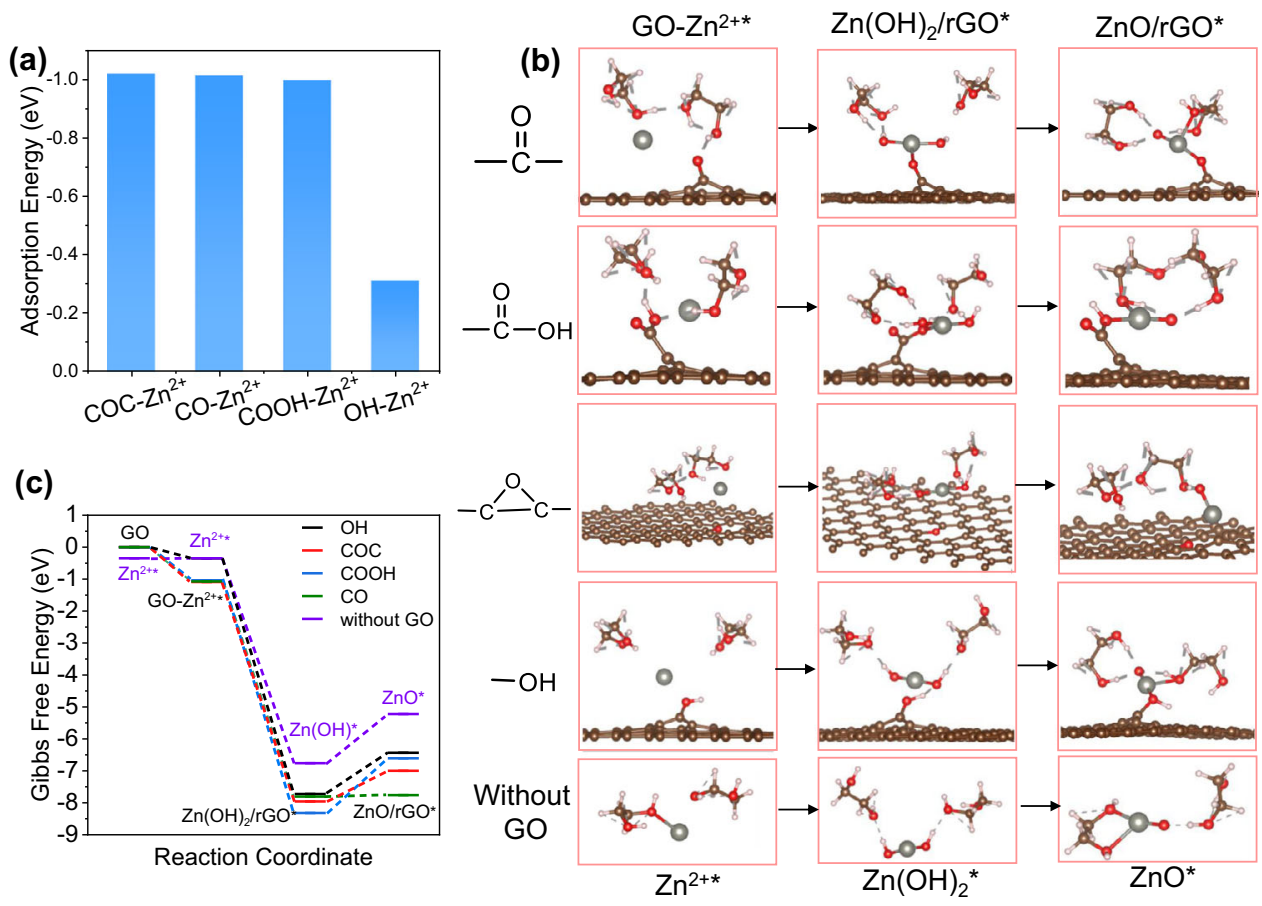

Fig. 3 DFT calculations of the formation of ultrafine $\mathbf{Z n O}$ nanoparticles on $\mathbf{G O}$ surface. a Adsorption Energy of $\mathrm{Zn}^{2+}$ on oxygen functional groups. $\mathbf{b}$ The optimized adsorption conformations of intermediate species on GO surface oxygen functional groups and in the absence of GO in EG. Zn, C, O and $\mathrm{H}$ atoms are represented by gray, brown, oxygen, and pink balls, respectively. c Energy profiles for the formation of ZnO nanoparticles on GO surface functional groups and in the absence of GO in EG.

(Supplementary Figs. 12, 13), large and aggregated particles are formed on the wrinkled rGO surface.

General synthesis of ultrafine metal oxide/rGO nanocomposites. Based on the above discussion, the oxygen functional groupsinduced heterogenous nucleation should work as a general strategy for the synthesis of other metal oxide/rGO nanocomposites. Herein, a family of nanocomposites with ultrafine metal oxide nanoparticles grown on $\mathrm{rGO}$ surface are successfully prepared, including $\mathrm{CdO} /$ $\mathrm{rGO}, \mathrm{CoO} / \mathrm{rGO}, \mathrm{CuO} / \mathrm{rGO}, \mathrm{Fe}_{2} \mathrm{O}_{3} / \mathrm{rGO}, \mathrm{MgO} / \mathrm{rGO}, \mathrm{La}_{2} \mathrm{O}_{3} / \mathrm{rGO}$, $\mathrm{MoO}_{3} / \mathrm{rGO}$, and $\mathrm{Nb}_{2} \mathrm{O}_{5} / \mathrm{rGO}$. As shown in Fig. 4a-h and Supplementary Figs. 14, 15, TEM images verify that all nanocomposites consist of monodispersed ultrafine metal oxide nanoparticles with the size less than $3 \mathrm{~nm}$. Moreover, metal sulfide nanoparticles $/ \mathrm{rGO}$ nanocomposites, such as $\mathrm{ZnS} / \mathrm{rGO}$ and $\mathrm{MoS}_{2} / \mathrm{rGO}$ could also be prepared by the present strategy through adding the thiourea in the precursor solution, as shown in Fig. 4i, j and Supplementary Fig. 16.

The synthetic procedures reported in this work are highly reproducible and readily applicable for the large-scale synthesis of ultrafine metal oxide/rGO nanocomposites. And more importantly, due to the effective inhibition of wrinkling of the rGO sheets, the as-prepared nanocomposites are highly dispersed into EG, forming a homogenous colloidal suspension of ca. $4 \mathrm{mg} / \mathrm{ml}$ without obvious sedimentation even after 1 month (Fig. 4k). Furthermore, the as-prepared nanocomposites could be also dispersed in the organic solvent such as $\mathrm{N}, \mathrm{N}$-dimethylformamide (DMF), isopropanol or N-methylpyrrolidone (NMP), which are desirable for wet processing to enable a homogenous arrangement of nanocomposites as filler, coatings, or thin films.

Preparation and characterization of $\mathrm{ZnO} / \mathrm{rGO}$ membranes. The free-standing $\mathrm{ZnO} / \mathrm{rGO}$ nanocomposite membranes were fabricated by a simple vacuum filtration of homogenous colloidal suspensions. After that, being washed with ethanol and dried at $60{ }^{\circ} \mathrm{C}$, the $\mathrm{ZnO} / \mathrm{rGO}$ membrane with $45 \mathrm{~mm}$ diameter is obtained
(Fig. 5a). This membrane can randomly bend $360^{\circ}$, suggesting its excellent flexibility and durability. SEM images (Fig. 5b) indicate that the resulting membrane is continuous and free of macropores or surface defects. And the cross-section image (Fig. 5c) demonstrates a layered structure resembling that of nacre, therefore exhibiting good mechanical strength. Such layered structure should be due to the continuous suction force from vacuum pump, which can move the solvent rapidly that can overcome the agglomeration of nanocomposites and form the laminated membranes. In addition, the surfaces of rGO nanosheets parallel to the basic membranes are more kinetically favorable than that of the nanosheets perpendicular to the membranes ${ }^{41-43}$

The distance between $\mathrm{ZnO} / \mathrm{rGO}$ bilayer is $\sim 4.6 \mathrm{~nm}$ determined by AFM images (Fig. 5d, e). By subtracting the rGO monolayer (ca. $0.34-0.4 \mathrm{~nm})^{23}$, the $2 \mathrm{D}$ nanochannel spacing of $\mathrm{ZnO} / \mathrm{rGO}$ membrane is estimated at $\sim 4.2 \mathrm{~nm}$, which is five times that of GO membranes (Supplementary Fig. 20 and Fig. 2 g). In addition, the roughness of $\mathrm{GO}$ and $\mathrm{ZnO} / \mathrm{rGO}$ membranes are given in Supplementary Table 2. Compared with GO membranes, $\mathrm{ZnO} /$ rGO membranes show obviously increasing roughness degree, which is due to the insertion of rigid $\mathrm{ZnO}$ nanoparticles. Furthermore, the interlayer spacings between nanosheets as pores are evaluated by nitrogen adsorption-desorption measurement. As shown in Fig. 5f, $\mathrm{ZnO} / \mathrm{rGO}$ membrane displays a Type IV sorption isotherm with Type $\mathrm{H} 3$ hysteresis ${ }^{44}$, responding to the slit-shaped pores between nanosheets. The resulting $\mathrm{BJH}$ pore size distribution reveals that the average pore size is at $\sim 4.0 \mathrm{~nm}$, which is consistent with AFM results.

Nanofiltration performance of $\mathrm{ZnO} / \mathrm{rGO}$ membranes. GO-based membranes are great promising for advanced nanofiltration in water treatments, however, their narrow interlayer channels generally limit the water flux and the separation of larger organic molecules 45 Generally, the separation mechanism of GO membranes is governed 

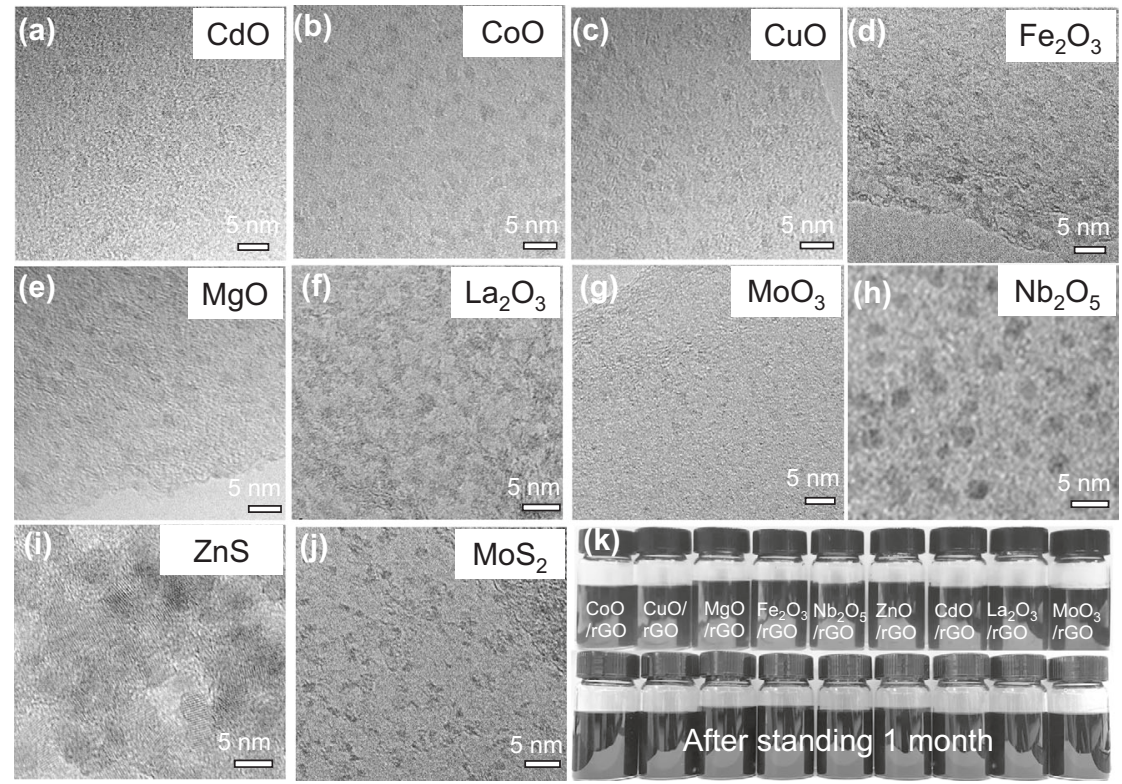

Fig. 4 Characterization of other ultrafine metal oxide/rGO nanocomposites. TEM images of (a) $\mathrm{CdO} / \mathrm{rGO},(\mathbf{b}) \mathrm{CoO} / \mathrm{rGO},(\mathbf{c}) \mathrm{CuO} / \mathrm{rGO},(\mathbf{d}) \mathrm{Fe} \mathrm{O}_{3} / \mathrm{rGO}$, (e) $\mathrm{MgO} / \mathrm{rGO}$, (f) $\mathrm{La}_{2} \mathrm{O}_{3} / \mathrm{rGO}$, (g) $\mathrm{MoO}_{3} / \mathrm{rGO}$, (h) $\mathrm{Nb}_{2} \mathrm{O}_{5} / \mathrm{rGO}$, (i) $\mathrm{ZnS} / \mathrm{rGO}$, and (j) $\mathrm{MoS}_{2} / \mathrm{rGO}$ nanocomposites, respectively. $\mathbf{k}$ Colloidal solutions of various metal oxide/rGO after and before standing 1 month.
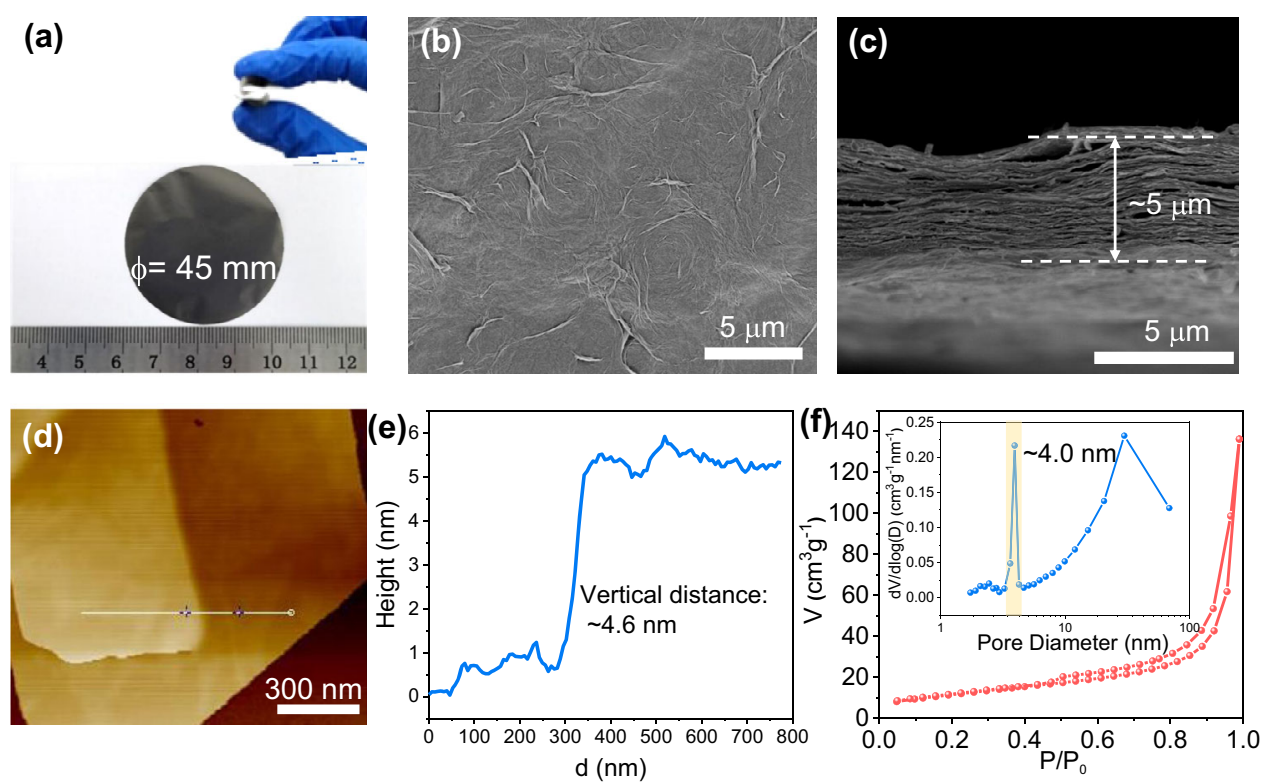

Fig. 5 Characterizations of ZnO/rGO membranes. a Digital photographs of the ZnO/rGO membranes, (b) top-view SEM image, and (c) cross-section SEM image of $\mathrm{ZnO} / \mathrm{rGO}$ membranes. d, e AFM images of $\mathrm{ZnO} / \mathrm{rGO}$ membranes. $\mathbf{f} \mathrm{N}_{2}$ adsorption-desorption isotherm and corresponding pore size distribution (inset) of $\mathrm{ZnO} / \mathrm{rGO}$ membranes.

primarily by the interlayer spacing between the nanosheets and the length or tortuosity of the transport pathways ${ }^{46}$. By functioning as pillars, the metal oxide nanoparticles remarkably increase both vertical interlayer spacing and lateral tortuous paths of the rGO membranes, offering the great possibility for the membranes concurrently with high water permeance and high rejections (as illustrated in Fig. 6).

To evaluate the separation performance, we fabricated the $\mathrm{ZnO} / \mathrm{rGO}$ membranes supported by nylon substrates and used them for dye permeation tests. As shown in Supplementary Fig. 21, $\mathrm{ZnO} / \mathrm{rGO}$ membranes with the layer-by-layer structure are tightly coated on a porous nylon $66-0.22 \mu \mathrm{m}$ substrate via vacuum filtration with $1 \mathrm{bar}$ vacuum. The surface wettability of $\mathrm{ZnO} / \mathrm{rGO}$ membranes is determined to be ca. $46^{\circ}$ by the water contact angle (Supplementary Fig. 22), indicating excellent hydrophilic properties. Due to the supporting of porous nylon, the large-area $\mathrm{ZnO} / \mathrm{rGO}$ membranes with the diameter of ca. $75 \mathrm{~mm}$ can also be manufactured (Supplementary Fig. 23). In addition, the loading mass of $\mathrm{ZnO} / \mathrm{rGO}$ on nylon membranes can be changed from 0.14 to $0.58 \mathrm{mg} \mathrm{cm}^{-2}$ by varying the volume of colloidal dispersion during the vacuum filtration. The average thicknesses of the $\mathrm{ZnO} / \mathrm{rGO}$ membranes are in the range of nanometers $(220 \mathrm{~nm})$ to micrometers $(1.1 \mu \mathrm{m})$ estimated by the SEM observation (Supplementary Fig. 23). 

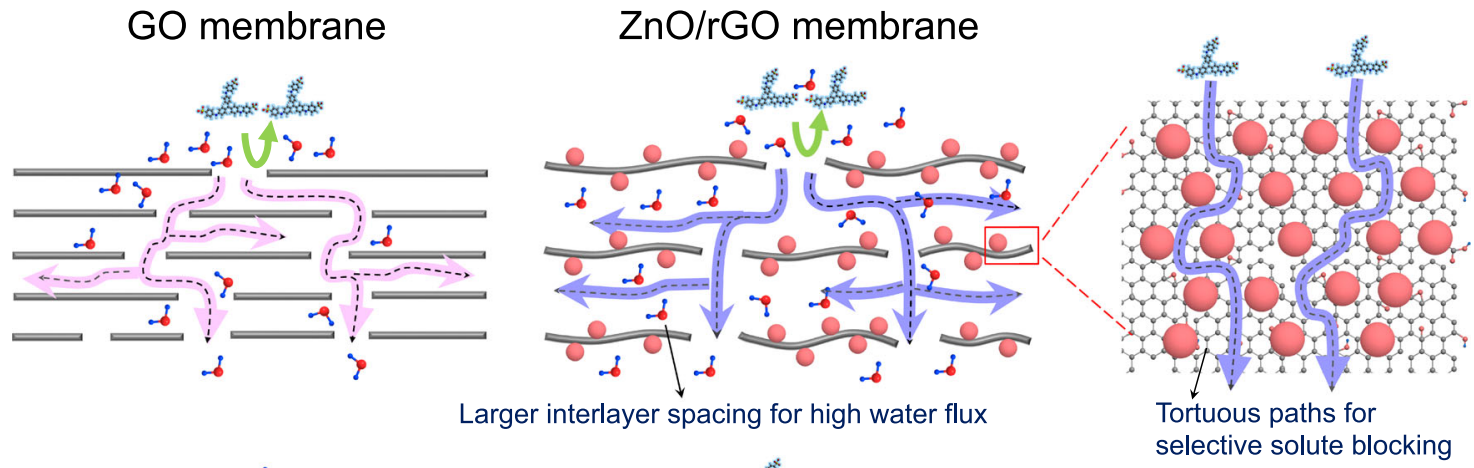

\& Water ZnO nanoparticle Methyl blue molecule

Fig. 6 Schematic illustration of separation mechanism and water transport through $\mathbf{G O}$ membranes and $\mathrm{ZnO} / \mathrm{rGO}$ membranes. Insertion of rigid $\mathrm{ZnO}$ nanoparticles between $\mathrm{rGO}$ layers increase both the interlayer spacings and in-plane obstructor of $\mathrm{rGO}$ layers, leading to higher water permeance and dye molecule selectivity. The green arrows represent the rejection of MB (methyl blue) molecules, the pink arrow represents flow path of water in GO membranes, and the purple arrows represent flow path of water in $\mathrm{ZnO} / \mathrm{rGO}$ membranes.

Due to the variations in transport distance, the loading mass of nanosheets has a critical effect on the water flux and the rejection rate of methyl blue (MB), as shown in Fig. 7a. With the increase of the $\mathrm{ZnO} / \mathrm{rGO}$ loading mass, the rejection rate increased from $69 \%$ to 98.1\%, while water flux decreases from 390 to $190 \mathrm{~L} \mathrm{~m}^{-2} \mathrm{~h}^{-1} \mathrm{bar}^{-1}$. Therefore, we select the optimized loading mass of ca. $0.54 \mathrm{mg} \mathrm{cm}^{-2}$ for further performance evaluation, which achieve simultaneously an extraordinary high water flux of $225 \mathrm{~L} \mathrm{~m}^{-2} \mathrm{~h}^{-1} \mathrm{bar}^{-1}$ and $\mathrm{MB}$ rejection of $98.1 \%$. To highlight the advanced performance of $\mathrm{ZnO} /$ rGO membranes, the pure GO membranes at the same mass loadings are prepared, which exhibits only $20 \mathrm{~L} \mathrm{~m}^{-2} \mathrm{~h}^{-1} \mathrm{bar}^{-1}$ water permeance as given in Fig. 7b. Moreover, the MB rejections of other reported GO-based membranes are compared in Fig. 7c and Supplementary Table 2. Except the exciting rejection rate, the $\mathrm{ZnO} / \mathrm{rGO}$ membranes exhibit much higher water permeance than those of the GO-based membranes reported so far (generally less than $\left.80 \mathrm{~L} \mathrm{~m}^{-2} \mathrm{~h}^{-1} \mathrm{bar}^{-1}\right)^{47-57}$.

Molecular selectivity is one of crucial parameters for the nanofiltration. Here we select a range of dye molecules with different weights $(319.85 \sim 960 \mathrm{Da})$ including evans blue (EB), congo red (CR), Rhodamine B (RhB), chrome black T (CBT), methyl orange (MO), and methylene blue (MLB) comparison. Their chemical structures, surface charge, and molecular sizes are given in Supplementary Table 3. As shown in Fig. $7 \mathrm{~d}$, the $\mathrm{ZnO} / \mathrm{rGO}$ membranes still exhibit remarkable high rejections of $>95 \%$ for $\mathrm{EB}$, $\mathrm{CR}, \mathrm{RhB}$, and CBT at high water permeances of $\sim 220 \mathrm{~L} \mathrm{~m}^{-2} \mathrm{~h}^{-1}$ $\mathrm{bar}^{-1}$, regardless of solute charge properties. However, in the case of MO and MLB with small molecular size of $1.13 \times 0.42 \mathrm{~nm}$ and $1.25 \times 0.51 \mathrm{~nm}$, the $\mathrm{ZnO} / \mathrm{rGO}$ membranes show only $27 \%$ and $20 \%$ rejection as a result of ineffective sieving effects for smaller molecules. Furthermore, the separation of a mixed solution of methyl blue/methyl orange (MB/MO) was carried out. As shown in Supplementary Fig. 26, the $\mathrm{ZnO} / \mathrm{rGO}$ membranes remain $\mathrm{MB}$ rejection of $98 \%$ and MO rejection of $25 \%$, being similar to the results of single component solution filtration test.

The membrane potential for extreme $\mathrm{pH}$ nanofiltration is key to practical applications. Here, we carried out the performance of $\mathrm{ZnO} / \mathrm{rGO}$ membranes at $\mathrm{MB}$ feed $\mathrm{pH}$ values from 2 to 8 , as shown in Fig. 7e. Under a board $\mathrm{pH}$ condition, $\mathrm{ZnO} / \mathrm{rGO}$ membranes still have an extraordinary high water flux of $\sim 225 \mathrm{~L} \mathrm{~m}^{-2} \mathrm{~h}^{-1} \mathrm{bar}^{-1}$ and MB rejection of $\sim 98 \%$. Furthermore, the mechanical stability of nanofiltration membranes is also very critical in practical applications. The long-term stability of $\mathrm{ZnO} /$ rGO and GO membranes of pure water were also conducted over a duration of $30 \mathrm{~h}$. As shown in Fig. 7f, the GO membranes deliver an initial water flux of $20 \mathrm{~L} \mathrm{~m}^{-2} \mathrm{~h}^{-1} \mathrm{bar}^{-1}$ and then decline rapidly to $3 \mathrm{~L} \mathrm{~m}^{-2} \mathrm{~h}^{-1} \mathrm{bar}^{-1}$, due to the compression of loosely overlapped GO nanosheets under pressure. In contrast, the rigid $\mathrm{ZnO}$ nanoparticles could serve as rigid "pillars" to create permanent high-speed waterways along the surface of rGO nanosheets, achieving a high steady-state flux value of $160 \mathrm{~L} \mathrm{~m}^{-2} \mathrm{~h}^{-1}$ bar $^{-1}$ after steadily $30 \mathrm{~h}$ working.

\section{Discussion}

The separation mechanism of $\mathrm{ZnO} / \mathrm{rGO}$ membranes for dye molecules should be dominated by size-exclusion selectivity, based on the counteracting roles of enlarging interlayer spacing and in-plane steric effects both caused by high-density loading of ultrafine $\mathrm{ZnO}$ nanoparticles. Water molecules could easily pass through the spaces between the pillars, while large-molecular dyes are selectively blocked based on their size and shape. The $\mathrm{ZnO} /$ rGO membranes thus address the critical trade-off between water flux and dye rejection in contrast to conventional nanofiltration membranes. Furthermore, the membrane microstructure could be adjusted by using different nanoparticle sizes and loadings, allowing us to control both the height and width of the paths between the pillars, thereby offering the great possibility towards on-demand nanofiltration applications.

In conclusion, we demonstrate a general and facile method to synthesize ultrafine metal oxide/rGO nanocomposites through heterogenous nucleation and growth process for nanofiltration applications. The key to the present synthesis is employing the oxygen functional groups on GO, which have binding ability toward $\mathrm{Zn}^{2+}$ through electrostatic attractions, and sequential triggers the heterogenous nucleation. Another important merit of the present synthesis is the effective inhibition of wrinkling and stacking of the resulting rGO sheets via the uniform adhesion of these ultrafine metal oxide nanoparticles. The adhesion of these metal oxide nanoparticles not only leads to physical separation of the rGO sheets, but also forms stable dispersions for wet processing of the membranes. Water molecules could easily pass through the narrow spaces between the nanoparticles, while large-molecular dyes are selectively rejected based on their size and shape. Moreover, the membrane microstructure can be turned vertically and laterally by using different sizes and loadings of metal oxide nanoparticles, extending their great potentials for on-demand applications such as water treatment, solvent dehydration, and organics sieving.

\section{Methods}

Chemicals. All chemicals were of analytic grade. Zinc Acetate Dihydrate was purchased from General-Reagent. Lanthanum (III) acetate hydrate $\left(\mathrm{La}(\mathrm{Ac})_{3} \cdot 6 \mathrm{H}_{2} \mathrm{O}\right)$, 

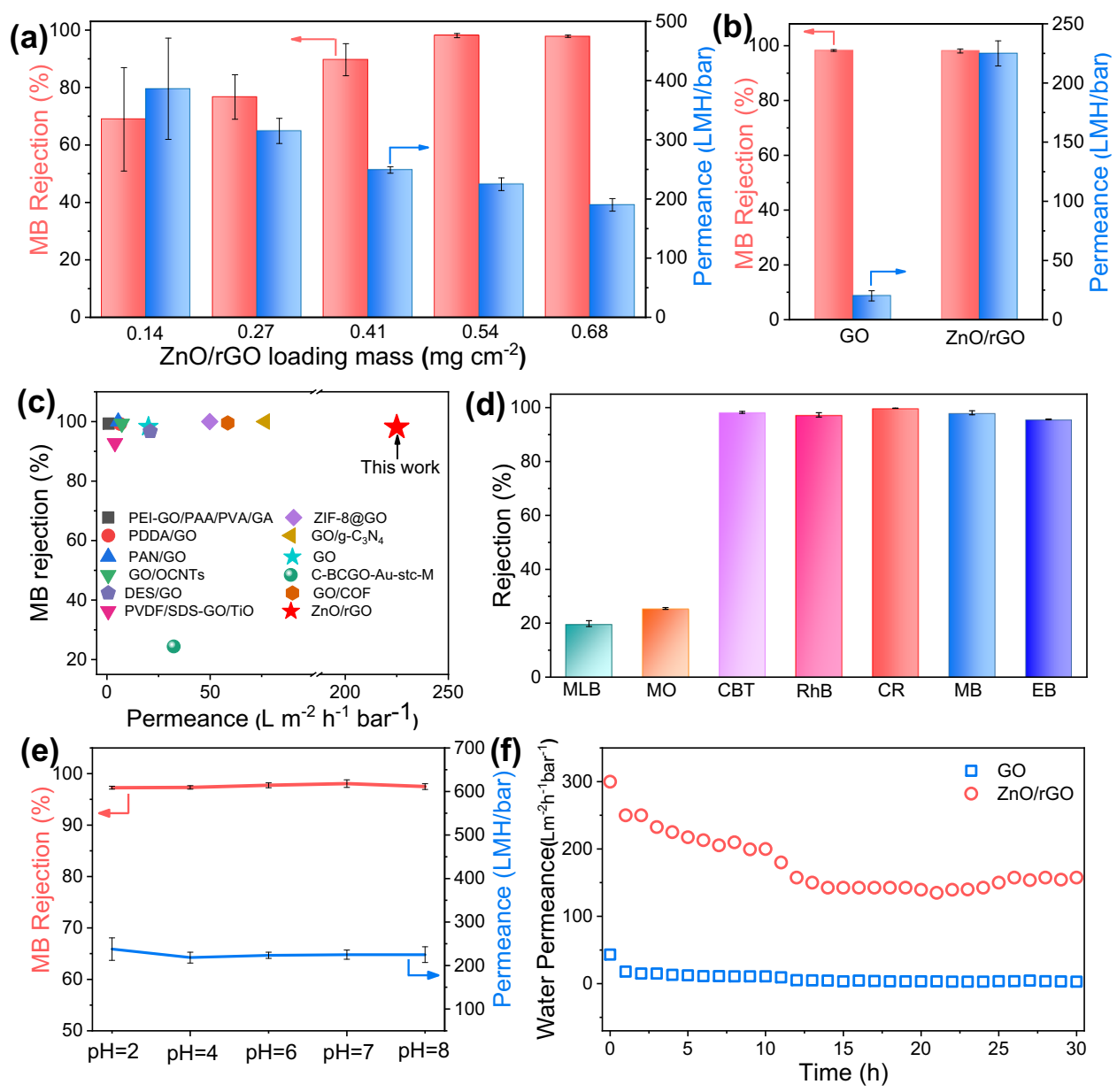

Fig. 7 Nanofiltration performance of $\mathbf{Z n O} / \mathbf{r G O}$ and $\mathbf{G O}$ membranes. a Water permeance and $\mathrm{MB}$ (methyl blue) rejection for $\mathrm{ZnO} / \mathrm{rGO}$ membranes with different loading mass. The blue and red arrows represent data corresponding to water permeance and $M B$ rejection, respectively. Error bars represent standard deviations from measurements of three different samples. b Water permeance and MB rejection for $\mathrm{ZnO} / \mathrm{rGO}$ membranes and GO membranes. Error bars represent standard deviations from measurements of three different samples. c Comparation of water permeance and $M B$ rejection of reported GO-based membranes. d Separation performance of $\mathrm{ZnO} / \mathrm{rGO}$ for dye molecules of varying molecular weight: Evans Blue (EB, $\mathrm{MW}=960), \mathrm{Methyl} B l u e$ $\left(M B, M_{W}=799.8\right)$, Congo Red $\left(C R, M_{W}=696\right)$, Rhodamine $B\left(R h B, M_{W}=479\right)$, Chrome Black $T\left(C B T, M_{W}=461\right), M e t h y l$ Orange $\left(M O, M_{W}=327\right)$ and Methylene Blue (MLB, $\left.M_{W}=319.85\right)$. Error bars represent standard deviations from measurements of three different samples. e Water permeance and $\mathrm{MB}$ rejection for $\mathrm{ZnO} / \mathrm{rGO}$ membranes at different $\mathrm{pH}$ values. Error bars represent standard deviations from measurements of three different samples. f Pure water permeance of $\mathrm{ZnO} / \mathrm{rGO}$ membranes and $\mathrm{GO}$ membranes over a $30 \mathrm{~h}$ operating period.

ammonium molybdate (VI) tetrahydrate $\left(\mathrm{Mo}_{7} \mathrm{O}_{24}\left(\mathrm{NH}_{4}\right)_{6}\right)$, chromium (II) acetate dihydrate $\left(\mathrm{Cd}(\mathrm{Ac})_{2} \cdot 2 \mathrm{H}_{2} \mathrm{O}\right)$, cobalt (II) acetate tetrahydrate $\left(\mathrm{Co}(\mathrm{Ac})_{2} \cdot 4 \mathrm{H}_{2} \mathrm{O}\right)$, cupric (II) acetate monohydrate $\left(\mathrm{Cu}(\mathrm{Ac})_{2} \cdot \mathrm{H}_{2} \mathrm{O}\right)$, ferric (II) acetate tetrahydrate $\left(\mathrm{Fe}(\mathrm{Ac})_{2} \cdot 4 \mathrm{H}_{2} \mathrm{O}\right)$, magnesium (II) acetate $\left(\mathrm{Mg}(\mathrm{Ac})_{2}\right)$, and ethylene glycol (EG) were purchased from Macklin. Niobium (V) pentachloride $\left(\mathrm{NbCl}_{5}\right)$ was purchased from Adamas-beta. All chemicals were used without further purification.

Synthesis of ultrafine $\mathrm{ZnO} / \mathrm{rGO}$ nanocomposites. The GO suspension was provided by The Institute of Coal Chemistry, Chinese Academy of Sciences and prepared by a modified Hummers method from natural graphite ${ }^{58}$. The as-prepared GO nanosheets were frozen-dried under $-90^{\circ} \mathrm{C}$ and then dispersed into $\mathrm{EG}$ under ultrasonic and magnetic stirring to form a homogenous solution of $5 \mathrm{mg} / \mathrm{ml}$. And $0.27 \mathrm{~g}$ zinc acetate dihydrate $\left(\mathrm{Zn}(\mathrm{Ac})_{2} \cdot 2 \mathrm{H}_{2} \mathrm{O}\right)$ was dissolved in a $30 \mathrm{~mL}$ EG solution with ultrasound for $1 \mathrm{~h}$ to form a transparent solution. Then, the above $\mathrm{Zn}(\mathrm{Ac})_{2} \cdot 2 \mathrm{H}_{2} \mathrm{O} /$ EG solution was added to $25 \mathrm{~mL} 5 \mathrm{mg} / \mathrm{ml} \mathrm{GO/EG}$ solution dropwise. After continuous magnetic stirring for about $2 \mathrm{~h}$, the resultant solution $55 \mathrm{~mL} \mathrm{Zn} \mathrm{(Ac)})_{2}$-GO/EG solution was transferred into a $100 \mathrm{~mL}$ Teflon-lined stainless-steel autoclave and heated at $180^{\circ} \mathrm{C}$ for $24 \mathrm{~h}$. After cooling down to room temperature naturally, the ultrafine $\mathrm{ZnO} /$ rGO nanocomposites were obtained. The designed $\mathrm{ZnO}$ content in the composite is $50 \%$.

In a control experiment, the solvothermal time was changed to $0.5 \mathrm{~h}, 1 \mathrm{~h}, 2 \mathrm{~h}$, $3 \mathrm{~h}, 8 \mathrm{~h}$, and $12 \mathrm{~h}, \mathrm{ZnO} / \mathrm{rGO}-1 \mathrm{~h}, \mathrm{ZnO} / \mathrm{rGO}-2 \mathrm{~h}, \mathrm{ZnO} / \mathrm{rGO}-3 \mathrm{~h}, \mathrm{ZnO} / \mathrm{rGO}-8 \mathrm{~h}$, and $\mathrm{ZnO} / \mathrm{rGO}-12 \mathrm{~h}$ were obtained, respectively. The samples prepared at different temperatures of $90^{\circ} \mathrm{C}, 120^{\circ} \mathrm{C}$, and $150^{\circ} \mathrm{C}$ were denoted as $\mathrm{ZnO} / \mathrm{rGO}-90^{\circ} \mathrm{C}, \mathrm{ZnO} /$ rGO- $120^{\circ} \mathrm{C}$, and $\mathrm{ZnO} / \mathrm{rGO}-150^{\circ} \mathrm{C}$, respectively. The samples prepared with different $\mathrm{Zn}(\mathrm{Ac})_{2} \cdot 2 \mathrm{H}_{2} \mathrm{O}$ weight of $0.12 \mathrm{~g}$ and $0.63 \mathrm{~g}$ were denoted as $\mathrm{ZnO} / \mathrm{rGO}-30 \%$ and $\mathrm{ZnO} / \mathrm{rGO}-70 \%$, respectively. The samples synthesized in different solvents of deionized water and ethanol were denoted as $\mathrm{ZnO} / \mathrm{rGO}-\mathrm{H}_{2} \mathrm{O}$ and $\mathrm{ZnO} / \mathrm{rGO}$ $\mathrm{EtOH}$. Pure $\mathrm{ZnO}$ was synthesized without adding GO/EG suspension in preparation.

Synthesis of other ultrafine metal oxide/rGO nanocomposites. All ultrafine metal oxide/rGO nanocomposites $\left(\mathrm{CdO} / \mathrm{rGO}, \mathrm{CoO} / \mathrm{rGO}, \mathrm{CuO} / \mathrm{rGO}, \mathrm{Fe}_{2} \mathrm{O}_{3} / \mathrm{rGO}\right.$, $\mathrm{MgO} / \mathrm{rGO}, \mathrm{La}_{2} \mathrm{O}_{3} / \mathrm{rGO}, \mathrm{MoO}_{3} / \mathrm{rGO}$, and $\mathrm{Nb}_{2} \mathrm{O}_{5} / \mathrm{rGO}$ ) were synthesized using the same process as that of ultrafine $\mathrm{ZnO} / \mathrm{rGO}$ nanocomposites, except that $\mathrm{Zn}(\mathrm{Ac})_{2} \cdot 2 \mathrm{H}_{2} \mathrm{O}$ was replaced by other metal salts $\left(\mathrm{Cd}(\mathrm{Ac})_{2} \cdot 2 \mathrm{H}_{2} \mathrm{O}, \mathrm{Co}(\mathrm{Ac})_{2} \cdot 4 \mathrm{H}_{2} \mathrm{O}, \mathrm{Cu}(\mathrm{Ac})_{2} \cdot \mathrm{H}_{2} \mathrm{O}\right.$, $\mathrm{Fe}(\mathrm{Ac})_{2} \cdot 4 \mathrm{H}_{2} \mathrm{O}, \mathrm{Mg}(\mathrm{Ac})_{2}, \mathrm{La}(\mathrm{Ac})_{3} \cdot 6 \mathrm{H}_{2} \mathrm{O}, \mathrm{Mo}_{7} \mathrm{O}_{24}\left(\mathrm{NH}_{4}\right)_{6} \cdot 4 \mathrm{H}_{2} \mathrm{O}$, and $\left.\mathrm{NbCl}_{5}\right)$. The designed contents of all metal oxide in nanocomposites are $50 \%$.

Synthesis of ultrafine metal sulfide/rGO nanocomposites. The ultrafine $\mathrm{ZnS} /$ $\mathrm{rGO}$ and $\mathrm{MoS}_{2} / \mathrm{rGO}$ nanocomposites were prepared in the same way of $\mathrm{ZnO} / \mathrm{rGO}$ and $\mathrm{MoO}_{3} / \mathrm{rGO}$ nanocomposites, respectively, through adding the thiourea in the precursor solution. The designed contents of all metal sulfide in nanocomposites are $50 \%$.

Preparation of $\mathrm{ZnO} / \mathrm{rGO}$ free-standing membranes. As-prepared ultrafine $\mathrm{ZnO} /$ rGO nanocomposites were dispersed into EG to form a homogenous solution ca. $0.34 \mathrm{mg} / \mathrm{ml}$. And then, the solution was vacuum filtered with polyvinylidene difluoride (PVDF) membranes. The wet $\mathrm{ZnO} / \mathrm{rGO}$ nanocomposites with PVDF membranes were fabricated and washed with ethanol several times. After being 
dried in $60^{\circ} \mathrm{C}$ for $12 \mathrm{~h}$, the $\mathrm{ZnO} / \mathrm{rGO}$ membranes could be peeled off as a freestanding membrane.

Materials characterizations. The morphologies and structures of nanocomposites were observed by using transmission electron microscopy (TEM, JEM-2100), scanning electron microscopy (SEM, Nova NanoSEM 450), and atomic force microscopy (AFM, MFP-3D). The thermogravimetric analysis (TGA 8000) was carried out at an air flow of $30 \mathrm{~mL} \mathrm{~min}^{-1}$ with heating from $30^{\circ} \mathrm{C}$ to $800^{\circ} \mathrm{C}$ at a rate of $10^{\circ} \mathrm{C} \mathrm{min}^{-1}$. The X-ray diffraction (XRD) patterns were obtained by using $\mathrm{Cu}$ Ka radiation $(\lambda=1.5406 \AA)$ on a Rigaku D/Mac 2550 diffractometer. The X-ray photoelectron spectroscopy (XPS) was carried out using ESCALAB 250Xi. Zeta potential pattern was obtained by using a Zetasizernano. The elemental composition was obtained from the CHN elemental analysis (Elementar Vario EL; Thermo Fisher). The $\mathrm{N}_{2}$ adsorption-desorption isotherm was carried out by ASAP2460, while the pore size was determined by Barrett-Joyner-Halenda (BJH) theory.

Density Functional Theory calculations. All the calculations were carried out by using the Perdew-Burke-Ernzerhof (PBE) function based on density functional theory (DFT) within the Vienna Ab Initio Simulation Package (VASP). To describe the electron-ion interactions, the cutoff energy of the plane wave was set as $400 \mathrm{eV}$. All atomic structures were allowed to relax until the maximum force was smaller than $0.02 \mathrm{eV} / \AA$ with the energy convergence criterion of $10^{-5} \mathrm{eV}$. And the $25 \AA$ was set as the thickness of vacuum layer to avoid periodic effects between mirror images. The graphene sheets containing defects were simulated by the $8 \times 8 \times 1$ supercells of repeated model. Integration of the Brillouin zone was performed by $1 \times 1 \times 1 \mathrm{k}$-point grids based on Gamma Scheme to obtain the optimized configuration and total energy of the system. What's more, Bader charge difference analysis was adopted to describe the charge transfer within the system.

The adsorption energy $\left(E_{\text {ads }}\right)$ was calculated according to the following equation:

$$
E_{\text {ads }}=E_{\text {adsorbate,sub }}-E_{\text {sub }}-E_{\text {adsorbate }}
$$

Where $E_{\text {adsorbate, sub }}$ represents the total energy of the adsorbate on the substrate, $E_{\text {sub }}$ represents the energy of the adsorbate, and $E_{\text {adsorbate }}$ represents the energy of the adsorbate.

The Gibbs free energy difference $(\Delta G)$ of reaction pathways was calculated according to the following equation:

$$
\Delta G=\Delta H+\Delta E_{\text {zpe }}-T \Delta S
$$

Where $\Delta H, \Delta E_{\text {zpe }}$, and $\Delta S$ are the difference of enthalpy, the zero-point energy, and the entropy of each elementary reaction, respectively. Set $T$ to the appropriate temperature in each calculation step. In addition, $\Delta E_{z p e}$ is attained through vibration frequency analysis.

Evaluation of nanofiltration performance. $\mathrm{ZnO} / \mathrm{rGO}$ and $\mathrm{GO}$ colloidal solutions were loaded on nylon substrates by a simple vacuum filtration. For vacuum filtration process, nylon membrane was firstly wetted by water, and then it was fixed onto the sand core of the suction filter equipment by a big holder. After that, highly dispersed $\mathrm{ZnO} / \mathrm{rGO}$ (or GO) solution was poured onto the surface of nylon membrane with a loading mass of $0.54 \mathrm{mg} \mathrm{cm}^{-2}$ by controlling the volume of colloidal solutions $(0.34 \mathrm{mg} / \mathrm{ml})$ at $20 \mathrm{ml}$. At the same time, a vacuum pump was connected to make the liquid penetrating through the porous nylon membrane until no visible liquid on the surface of the membrane. Each membrane was analyzed in triplicates under the same conditions. The nanofiltration performance was determined using dead-end filtration of various dye solutions $(25 \mathrm{ppm})$. The $\mathrm{pH}$ of the solution was adjusted by $0.01 \mathrm{~mol} / \mathrm{L} \mathrm{HCL}$ and $\mathrm{KOH}$ solution. The feed and permeate concentrations were analyzed by ultraviolet-visible (UV-Vis) spectroscopy, which was measured at the maximal absorption wavelength of the five organic dyes.

Filtration characteristics, including water permeability $\left(J, \mathrm{~L} \mathrm{~m}^{-2} \mathrm{~h}^{-1} \mathrm{bar}^{-1}\right)$ and dye rejection $(R, \%)$, were calculated by the following equations:

$$
J=\frac{J_{W}}{\Delta P}=\frac{V}{A \times t \times \Delta P}
$$

Where $\mathrm{V}$ is the volume of permeate $(L)$, $\mathrm{A}$ is effective membrane area $\left(4 \times 10^{-4} \mathrm{~m}^{2}\right)$, $\mathrm{t}$ is the permeation time $(h)$, and $\Delta \mathrm{P}$ is the transmembrane pressure ( $1 \mathrm{bar}$ ).

$$
R_{(\%)}=\frac{C_{f}-C_{P}}{C_{f}} \times 100
$$

Where $C_{\mathrm{f}}$ and $C_{\mathrm{p}}$ are the concentrations of markers in the permeate and retentate solutions.

\section{Data availability}

The data that support findings from this study are available from the corresponding author on request.
Received: 25 August 2021; Accepted: 11 January 2022;

Published online: 25 January 2022

\section{References}

1. Al-Rashdi, B. A. M., Johnson, D. J. \& Hilal, N. Removal of heavy metal ions by nanofiltration. Desalination. 315, 2-17 (2013).

2. Marchetti, P. et al. Molecular separation with organic solvent nanofiltration: a critical review. Chem. Rev. 114, 10735-10806 (2014).

3. Radjenović, J. et al. Rejection of pharmaceuticals in nanofiltration and reverse osmosis membrane drinking water treatment. Water Res. 42, 3601-3610 (2008).

4. Nath, K., Dave, H. K. \& Patel, T. M. Revisiting the recent applications of nanofiltration in food processing industries: Progress and prognosis. Trends Food Sci. Technol. 73, 12-24 (2018).

5. Sun, S. P. et al. Polyamide-imide nanofiltration hollow fiber membranes with elongation-induced nano-pore evolution. AIChE J. 56, 1481-1494 (2009).

6. Baker, R. W., Membrane Technology and Applications, (John Wiley \& Sons, 2012).

7. Cheng, C., Iyengar, S. A. \& Karnik, R. Molecular size-dependent subcontinuum solvent permeation and ultrafast nanofiltration across nanoporous graphene membranes. Nat. Nanotechnol. 16, 989-995 (2021).

8. Pandey, R. P. et al. A fouling-resistant mixed-matrix nanofiltration membrane based on covalently cross-linked Ti3C2TX (MXene)/cellulose acetate. J. Membr. Sci. 607, 118139 (2020).

9. Akbari, A. et al. Large-area graphene-based nanofiltration membranes by shear alignment of discotic nematic liquid crystals of graphene oxide. Nat. Commun. 7, 1-12 (2016).

10. Zhu, Y. et al. Graphene and graphene oxide: synthesis, properties, and applications. Adv. Mater. 22, 3906-3924 (2010).

11. Yang, Y. et al. Large-area graphene-nanomesh/carbon-nanotube hybrid membranes for ionic and molecular nanofiltration. Science. 364, 1057-1062 (2019).

12. Yuan, Y. et al. Enhanced desalination performance of carboxyl functionalized graphene oxide nanofiltration membranes. Desalination. 405, 29-39 (2017).

13. Dubin, S. et al. A one-step, solvothermal reduction method for producing reduced graphene oxide dispersions in organic solvents. ACS Nano. 4, 3845-3852 (2010).

14. Feldmann, C. \& Jungk, H. O. Polyol-mediated preparation of nanoscale oxide particles. Angew. Chem. Int. Ed. 40, 359-362 (2001).

15. Hamilton, C. E. et al. High-yield organic dispersions of unfunctionalized graphene. Nano Lett. 9, 3460-3462 (2009).

16. Han, Y., Xu, Z. \& Gao, C. Ultrathin graphene nanofiltration membrane for water purification. Adv. Funct. Mater. 23, 3693-3700 (2013).

17. Huang, K. et al. A graphene oxide membrane with highly selective molecular separation of aqueous organic solution. Angew. Chem. 126, 7049-7052 (2014).

18. Liu, J. et al. Bioinspired graphene membrane with temperature tunable channels for water gating and molecular separation. Nat. Commun. 8, 1-9 (2017).

19. Zhang, L. et al. Fungal cell wall-graphene oxide microcomposite membrane for organic solvent nanofiltration. Adv. Funct. Mater. 31, 2100110 (2021).

20. Koenig, S. P. et al. Selective molecular sieving through porous graphene. Nat Nanotechnol. 7, 728-732 (2012).

21. Zheng, S. et al. Correlating interlayer spacing and separation capability of graphene oxide membranes in organic solvents. ACS Nano. 14, 6013-6023 (2020).

22. Iakunkov, A. \& Talyzin, A. V. Swelling properties of graphite oxides and graphene oxide multilayered materials. Nanoscale. 12, 21060-21093 (2020).

23. Qi, B. et al. Strict molecular sieving over electrodeposited 2D-interspacingnarrowed graphene oxide membranes. Nat. Commun. 8, 825 (2017).

24. Liu, H., Wang, H. \& Zhang, X. Facile fabrication of freestanding ultrathin reduced graphene oxide membranes for water purification. Adv. Mater. 27, 249-254 (2015).

25. Wei, Y. et al. Declining flux and narrowing nanochannels under wrinkles of compacted graphene oxide nanofiltration membranes. Carbon. 108, 568-575 (2016).

26. Karachevtsev, V. A. et al. Structural and spectral transformation of cationic porphyrin TMPyP4 at adsorption on graphene. J. Mol. Struct. 1245, 131056 (2021).

27. Zhang, W. et al. Soft particles enable fast and selective water transport through graphene oxide membranes. Nano Lett. 20, 7327-7332 (2020).

28. Dai, L. et al. Ultrafast water transport in two-dimensional channels enabled by spherical polyelectrolyte brushes with controllable flexibility. Angew. Chem. Int. Ed. Engl. 60, 19933-19941 (2021).

29. Shao, L. et al. Tuning the performance of polypyrrole-based solvent-resistant composite nanofiltration membranes by optimizing polymerization conditions and incorporating graphene oxide. J. Membr. Sci. 452, 82-89 (2014). 
30. Gao, T. et al. Enhanced stability and separation efficiency of graphene oxide membranes in organic solvent nanofiltration. J. Mater. Chem. A. 6, 19563-19569 (2018).

31. Lai, G. S. et al. Graphene oxide incorporated thin film nanocomposite nanofiltration membrane for enhanced salt removal performance. Desalination. 387, 14-24 (2016).

32. Aba, N. F. D. et al. Graphene oxide membranes on ceramic hollow fibers-Microstructural stability and nanofiltration performance. J. Membr. Sci. 484, 87-94 (2015).

33. Bagri, A. et al. Structural evolution during the reduction of chemically derived graphene oxide. Nat. Chem. 2, 581-587 (2010).

34. Xue, Y. et al. Multiscale patterning of graphene oxide and reduced graphene oxide for flexible supercapacitors. Carbon. 92, 305-310 (2015).

35. Dikin, D. A. et al. Preparation and characterization of graphene oxide paper. Nature. 448, 457-460 (2007).

36. Pei, S. \& Cheng, H.-M. The reduction of graphene oxide. Carbon. 50, 3210-3228 (2012).

37. Chua, C. K. \& Pumera, M. Chemical reduction of graphene oxide: a synthetic chemistry viewpoint. Chem. Soc. Rev. 43, 291-312 (2014).

38. Bae, G. et al. Complementary dual-channel gas sensor devices based on a roleallocated $\mathrm{ZnO} /$ graphene hybrid heterostructure. ACS Appl. Mater. Interfaces 11, 16830-16837 (2019).

39. Qi, X. et al. Conjugated-polyelectrolyte-functionalized reduced graphene oxide with excellent solubility and stability in polar solvents. Small. 6, 663-669 (2010).

40. $\mathrm{Ma}, \mathrm{Q}$. et al. Colloidal dispersion of $\mathrm{Nb} 2 \mathrm{O} 5 /$ reduced graphene oxide nanocomposites as functional coating layer for polysulfide shuttle suppression and lithium anode protection of Li-S battery. J Colloid Interface Sci. $\mathbf{5 6 6}$ 11-20 (2020)

41. Eda, G., Fanchini, G. \& Chhowalla, M. Large-area ultrathin films of reduced graphene oxide as a transparent and flexible electronic material. Nat. Nanotechnol. 3, 270-274 (2008).

42. Joshi, R. K. et al. Precise and ultrafast molecular sieving through graphene oxide membranes. Science. 343, 752-754 (2014).

43. Karan, S. et al. Ultrafast viscous permeation of organic solvents through diamond-like carbon nanosheets. Science. 335, 444-447 (2012).

44. Paek, S.-M., Yoo, E. \& Honma, I. Enhanced cyclic performance and lithium storage capacity of $\mathrm{SnO} 2 /$ graphene nanoporous electrodes with threedimensionally delaminated flexible structure. Nano Lett. 9, 72-75 (2009).

45. Wang, Z. et al. Graphene oxide nanofiltration membranes for desalination under realistic conditions. Nat. Sustain. 4, 402-408 (2021)

46. Shen, J. et al. Artificial channels for confined mass transport at the subnanometre scale. Nature Reviews. Materials. 6, 294-312 (2021).

47. Chen, L., et al. High performance hierarchically nanostructured graphene oxide/covalent organic framework hybrid membranes for stable organic solvent nanofiltration. Appl. Mater. Today. 20, 100791 (2020).

48. Kang, H. et al. Sandwich morphology and superior dye-removal performances for nanofiltration membranes self-assemblied via graphene oxide and carbon nanotubes. Appl. Surf. Sci. 428, 990-999 (2018).

49. Mehrabi, N., H. Lin, and N. Aich. Deep eutectic solvent functionalized graphene oxide nanofiltration membranes with superior water permeance and dye desalination performance. Chem. Eng. J. 412, 128577 (2021).

50. Qiu, Z., Ji, X. \& He, C. Fabrication of a loose nanofiltration candidate from Polyacrylonitrile/Graphene oxide hybrid membrane via thermally induced phase separation. J Hazard Mater. 360, 122-131 (2018).

51. Suriani, A. B. et al. Incorporation of electrochemically exfoliated graphene oxide and $\mathrm{TiO} 2$ into polyvinylidene fluoride-based nanofiltration membrane for dye rejection. Water Air Soil Pollut. 2019. 230, 1-13 (2019).

52. Wang, L. et al. Layer-by-layer self-assembly of polycation/GO nanofiltration membrane with enhanced stability and fouling resistance. Sep. Purif. Technol. 160, 123-131 (2016).

53. Wang, N. et al. Self-assembly of graphene oxide and polyelectrolyte complex nanohybrid membranes for nanofiltration and pervaporation. Chem. Eng. J. 213, 318-329 (2012).
54. Wu, Y. et al. 2D heterostructured nanofluidic channels for enhanced desalination performance of graphene oxide membranes. ACS Nano. 15 7586-7595 (2021)

55. Yang, K. et al. Graphene oxide nanofiltration membranes containing silver nanoparticles: tuning separation efficiency via nanoparticle size. Nanomaterials. 10, 454 (2020).

56. Zhang, W. H. et al. Graphene oxide membranes with stable porous structure for ultrafast water transport. Nat. Nanotechnol. 16, 337-343 (2021).

57. Zhong, Y. et al. Graphene oxide modified membrane for highly efficient wastewater treatment by dynamic combination of nanofiltration and catalysis. J. Hazard Mater. 397, 122774 (2020).

58. Marcano, D. C. et al. Improved ynthesis of graphene oxide. ACS Nano. 4, 4806-4814 (2010)

\section{Acknowledgements}

This work was financially supported by funding from National Natural Science Foundation of China (No. 22078100, No. 21878091 and No. 22008073), and Fundamental Research Funds for the Central Universities.

\section{Author contributions}

D.L. supervised and conceived the idea and wrote the paper. B.N. supervised the project. W.Z. designed experiments, synthesized samples, carried out nanofiltration performance measurement and wrote the paper. X.H. performed the DFT calculations. F.X. and X.M. performed nanofiltration performance measurement. H.Z. performed the illustration of reaction process. M.C. and Y.Z. helped with the modification of the paper.

\section{Competing interests}

The authors declare no competing interests.

\section{Additional information}

Supplementary information The online version contains supplementary material available at https://doi.org/10.1038/s41467-022-28180-4.

Correspondence and requests for materials should be addressed to Bo Niu or Donghui Long.

Peer review information Nature Communications thanks Zongxue $\mathrm{Yu}$, and the other, anonymous, reviewer for their contribution to the peer review of this work.

Reprints and permission information is available at http://www.nature.com/reprints

Publisher's note Springer Nature remains neutral with regard to jurisdictional claims in published maps and institutional affiliations.

Open Access This article is licensed under a Creative Common Attribution 4.0 International License, which permits use, sharing, adaptation, distribution and reproduction in any medium or format, as long as you give appropriate credit to the original author(s) and the source, provide a link to the Creative Commons license, and indicate if changes were made. The images or other third party material in this article are included in the article's Creative Commons license, unless indicated otherwise in a credit line to the material. If material is not included in the article's Creative Commons license and your intended use is not permitted by statutory regulation or exceeds the permitted use, you will need to obtain permission directly from the copyright holder. To view a copy of this license, visit http://creativecommons.org/ licenses/by/4.0/

(C) The Author(s) 2022 